\title{
Vestibular Terminology and the Cause of Symptoms from a Chronic Perilymph Leak (Perilymph Fistula)
}

\author{
Jeremy Hornibrook (D) \\ Department of Otolaryngology-Head and Neck Surgery, Christchurch Hospital, Christchurch, New Zealand (Aotearoa)
}

Dear Editor,

The recent article 'Two cases of recurred vertigo following perilymphatic oval window fistula repair' by Kim and Chung ${ }^{1)}$ merits comment in regard to vestibular terminology and notions of what is the true cause of the symptoms of a chronic window perilymph leak (perilymph fistula, PLF).

PLF has been the most controversial and divisive topic in otolaryngology now for 60 years. ${ }^{2)}$ As an entity it is disbelieved by many, especially in the USA where in some centres residents are still taught it does not exist. In reality it is the most seriously disabling chronic vestibular condition and incompatible with leading a normal life.

The whole PLF field is discredited and confused by longstanding misuse of vestibular terminology. This can be forgiven in past years. More recently the Barany Society has commendably issued new unequivocal definitions for common vestibular symptoms ${ }^{3)}$ that should be followed by everyone. The important distinction is between dizziness and vertigo which many authors still use interchangeably. Dizziness: the sensation of disturbed or impaired special orientation without a false or distorted sense of motion. Vertigo: the sensation of self-motion when no self-motion is occurring or the sense of distorted self-motion during an otherwise normal head movement. These definitions do not involve balance, but many authors use dizziness as implying disordered balance. For balance unsteadiness is defined as the feeling of being unstable while seated, standing or walking without a particular directional preponderance. Unfortunately the Barany definitions disapprove of the old term disequilibrium and have replaced it with lateral pulsion which has a neurological basis. This is where the PLF problem arises because patients with a chronic perilymph leak do not have dizziness but have a unilateral disequilibrium, a loss of postural control to the symptomatic side. Therefore it is curious that the authors chose to reference an article $^{4)}$ on that very point, but not test for it.

The notion that the symptoms of a chronic perilymph leak are attributable to endolymphatic hydrops arose from mere speculation by Harrison, et al. ${ }^{5)}$ in 1967 and has been repeated ad infinitum by multiple authors. Many general patients have inner ear hydrops with no vestibular symptoms. That chronic PLF symptoms vanish immediately on repair makes hydrops as a cause most unlikely, but rather a chronic otolith organ dysfunction $^{4,6)}$ with possibly the floating labyrinth to explain it.

In fairness the management of Kim and Chung ${ }^{1)}$ two cases is not being criticised here. It seems both these patients initially presented with fairly typical symptoms of a chronic window perilymph leak. They both later exhibited likely true vertigo that can be explained by the abnormalities they found and corrected.

Routine radiological imaging of a tiny window leak is still not possible. Future imaging advances might solve that and also allow internal visualisation of the otolith organ behaviour the leak is causing. Meanwhile all vestibular clinicians should be scrupulous in their concept and use of correct vestibular symptom terminology, and for a suspected PLF carefully test the patient for impaired postural control. ${ }^{6}$

\section{Acknowledgments}

None.

Received: January 5, $2021 \quad$ Accepted: February 22, 2021

Address for correspondence: Jeremy Hornibrook, FRACS, Department of Otolaryngology-Head and Neck Surgery, Christchurch Hospital, 2 Riccarton Avenue, Christchurch Central City, Christchurch 8011, New Zealand (Aotearoa)

Tel: +64-3-3640125, Fax: +64-3-3640273, E-mail: jeremy@jhornibrook.com

This is an Open Access article distributed under the terms of the Creative Commons Attribution Non-Commercial License (https:/creativecommons.org/licenses/by-nc/4.0) which permits unrestricted non-commercial use, distribution, and reproduction in any medium, provided the original work is properly cited. 


\section{ORCID}

Jeremy Hornibrook https://orcid.org/0000-0002-5402-8725

\section{REFERENCES}

1) Kim HJ, Chung WH. Two cases of recurred vertigo following perilymphatic oval window fistula repair. Korean J OtorhinolaryngolHead Neck Surg 2021;64(2):103-7.

2) Hornibrook J. Perilymph fistula: Fifty years of controversy. ISRN Otolaryngol 2012;2012:281248.
3) Bisdorff A, Von Brevern M, Lempert T, Newman-Toker DE. Classification of vestibular symptoms: Towards an international classification of vestibular disorders. J Vestib Res 2009;19(1-2):1-13.

4) Hornibrook J. A balance test for chronic perilymph fistula. Int J Otolaryngol 2012;2012:163691.

5) Harrison WH, Shambaugh GE Jr, Derlacki EL, Clemis JD. Perilymph fistula in stapes surgery. Laryngoscope 1967;77(5):836-49.

6) Hornibrook J. The postural and cognitive disabilities of chronic perilymph fistula (PLF) after mild head trauma. An Clin Case Rep 2018;3:1514. 